\title{
Avaliação sorológica e de fatores de risco para a infecção por Mycobacterium avium subsp. paratuberculosis em rebanhos leiteiros da Microrregião de Garanhuns, Pernambuco ${ }^{1}$
}

\author{
Luenda de M. e Sá2, Júnior M.B. de Oliveira², Gislaine R. Santos ${ }^{2}$, Daniel F. Brandespim², \\ José L. da Silva Júnior ${ }^{3}$, Rinaldo A. Mota ${ }^{4}$ J José W. Pinheiro Júnior ${ }^{2 *}$
}

\begin{abstract}
Sá L.M., Oliveira J.M.B., Santos G.R., Brandespim D.F., Silva-Júnior J.L., Mota R.A. \& Pinheiro Júnior J.W. 2013. [Serological evaluation and risk factors for Mycobacterium avium subsp. paratuberculosis infection in dairy herds of Microregion Garanhuns, Pernambuco.] Avaliação sorológica e de fatores de risco para a infecção por Mycobacterium avium subsp. paratuberculosis em rebanhos leiteiros da Microrregião de Garanhuns, Pernambuco. Pesquisa Veterinária Brasileira 33(3):310-313. Universidade Federal Rural de Pernambuco, Unidade Acadêmica de Garanhuns, Av. Bom Pastor s/n, Boa Vista, Garanhuns, PE 55296-901, Brazil. E-mail: jrwilton@uag.ufrpe.br

The present study aimed to conduct an epidemiological investigation of Mycobacterium avium subsp. paratuberculosis (MAP) infection in dairy cattle of the Garanhuns microregion, in Pernambuco, Brazil. Blood samples were collected from 408 animals from 19 herds located in 15 cities. Serological tests were performed by indirect immunoenzymatic assay (ELISA) for antibodies against MAP. In all farms, a questionnaire to investigate risk factors was used, and Global Position System (GPS) receivers were used to collect geographic coordinates to show the spatial distribution of the animals. The prevalence of MAP infected cattle was $2.7 \%$ (11/408; I.C. 1.4-4.9). The rate of infection was $47.4 \%$ (9/19). An annual birth rate over 51 calves/year (OR 3.8; I.C. 1.1-13.1) was identified as a risk factor in logistic regression analysis. Thus, it is concluded that MAP infection is present in dairy cattle of the microregion studied here, and control measures based on the identified risk factors should be implemented in order to reduce the sources of infection.
\end{abstract}

INDEX TERMS: Mycobacterium avium subsp. paratuberculosis, Johne diseases, risk factors, MAP, cattle.

RESUMO.- Objetivou-se com esse trabalho realizar um inquérito epidemiológico da infecção por Mycobacterium avium subsp. paratuberculosis (MAP) em bovinos leiteiros da microrregião de Garanhuns, Pernambuco, Brasil. Para este estudo foram coletadas amostras sanguíneas de 408 animais, provenientes de 19 rebanhos localizados em 15 municípios. 0 exame sorológico foi realizado por Ensaio

\footnotetext{
${ }^{1}$ Recebido em 12 de outubro de 2012.

Aceito para publicação em 28 de janeiro de 2013.

${ }^{2}$ Unidade Acadêmica de Garanhuns, Universidade Federal Rural de Pernambuco (UFRPE), Av. Bom Pastor s/n, Boa Vista, Garanhuns, PE 55296901, Brasil. *Autor para correspondência: jrwilton@uag.ufrpe.br

${ }^{3}$ Divisão de Vigilância Epidemiológica e Análise de Risco (DVEAR), Agência de Defesa e Fiscalização Agropecuária de Pernambuco (Adagro), Av. Caxangá 2200, Cordeiro, PE 50711-000, Brasil.

${ }^{4}$ Departamento de Medicina Veterinária, UFRPE, Rua Dom Manoel de Medeiros s/n, Dois Irmãos, Recife, PE 52171-900.
}

Imunoenzimático (ELISA) indireto para detecção de anticorpos frente ao MAP. Em todas as propriedades, foi aplicado um questionário investigativo para análise dos fatores de risco, e as coordenadas geográficas coletadas por um aparelho de Global Position System (GPS) para realização da distribuição espacial. A prevalência da infecção por MAP foi de $2,7 \%(11 / 408$; I.C. 1,4-4,9). 0 número de focos foi $47,4 \%(9 / 19)$. Na análise de regressão logística foi identificado como fator de risco a taxa anual de nascimentos superior a 51 bezerros/ano (OR 3,8; I.C. 1,1-13,1). Desta forma, conclui-se que a infecção por MAP encontra-se presente nos rebanhos bovinos leiteiros da microrregião estudada e que medidas de controle baseadas nos fatores de risco identificados devem ser implementadas com o objetivo de reduzir o número de focos da infecção.

TERMOS DE INDEXAÇÃO: Mycobacterium avium subsp. paratuberculosis, doença de Johne, fatores de risco, MAP, bovinos. 


\section{INTRODUÇÃO}

A paratuberculose é uma enfermidade caracterizada por enterite granulomatosa crônica que acomete principalmente bovinos, ovinos, caprinos e ruminantes silvestres, sendo causada por Mycobacterium avium subsp. paratuberculosis (MAP), e se caracteriza por apresentar uma longa fase subclínica, ocasionando grandes perdas na produção (Bennett et al. 2012). É um dos principais problemas para a saúde dos ruminantes de todo mundo e causa significativas perdas econômicas para a indústria de laticínios (Janagama et al. 2010). No maior produtor de leite, EUA, essas perdas chegam a \$200 milhões de dólares por ano (Cho et al. 2012).

No Brasil relatos de paratuberculose em bovinos ocorreram no Rio de Janeiro (Dupont 1915, Santos \& Silva 1956, Darcoso-Filho et al. 1960, Silva \& Pizelli 1961, Yamasaki et al. 2010), Santa Catarina (Portugal et al. 1979), Rio Grande do Sul (Ramos et al. 1986, Driemeier et al. 1999), Minas Gerais (Nakajima et al. 1991), São Paulo (Fonseca et al. 1999), Paraíba (Dias et al. 2002, Mota et al. 2009, Oliveira et al. 2010, Medeiros et al. 2012), Goiás (Acypreste et al. 2005), Pará (Silva 2005), Espírito Santo (Costa et al. 2010) e Pernambuco (Mota et al. 2007).

Alguns fatores contribuem para a ocorrência da doença nos rebanhos, tais como, sistema de criação, tamanho do rebanho, volume de produção leiteira, manejo do rebanho (especialmente criação de animais jovens com adultos), estresse causado pela retirada diária do leite, transporte, parto, deficiências minerais e nutricionais e elevadas cargas parasitárias (Merkal 1975, Dufour et al. 2004). O contato direto de bezerros com fezes de vacas adultas infectadas por MAP, foi considerado por Doré et al. (2012), como o fator de risco mais importante na transmissão do agente aos bezerros.

Com a análise epidemiológica da infecção por MAP, espera-se subsidiar a elaboração de medidas profiláticas integradas, contribuindo significativamente para redução das perdas decorrentes da paratuberculose em bovinos leiteiros, visto que há poucos dados da mesma. Objetivou-se com esse trabalho relatar os aspectos epidemiológicos da infecção por MAP em bovinos leiteiros da microrregião de Garanhuns, Pernambuco, Brasil.

\section{MATERIAL E MÉTODOS}

O projeto foi aprovado no Comitê de Ética no Uso de Animais da Universidade Federal Rural de Pernambuco com a licença no $014 / 2010$.

Os animais foram procedentes de rebanhos leiteiros de 15 municípios da Microrregião de Garanhuns, estado de Pernambuco (Fig.1A). Foram analisados animais de 19 propriedades sem histórico de paratuberculose distribuídas nos municípios de Angelim (1), Bom Conselho (2), Caetés (1), Calçados (1), Canhotinho (1), Correntes (1), Garanhuns (2), Iati (2), Jucati (1), Lagoa do Ouro (1), Lajedo (1), Palmeirina (1), Saloá (2), São João (1) e Terezinha (1).

Para compor a amostra de estudo da prevalência foi considerado um total de 336.221 cabeças de bovinos na microrregião (IBGE 2006), admitiu-se uma prevalência esperada de 50\%, visto que não há dados da ocorrência da infecção na microrregião estudada, essa proporção maximizou o tamanho da amostra garan- tindo a confiança mínima de $95 \%$ e erro estatístico de 5\%, e esse parâmetro forneceu um tamanho de amostra (n) de 385 animais (Thrusfield 2004). Para o cálculo das amostras por propriedade utilizou-se o programa computacional WinEpiscope 2.0, utilizando-se os parâmetros de amostragem supracitados. Como margem de segurança foram coletadas 408 amostras de bovinos de raças produtoras de leite como Holandesas, Gir leiteiras e Girolandas, acima de dois anos de idade, com aptidão leiteira e submetidos a diferentes sistemas de manejo.

Antes de cada coleta foi aplicado em cada um dos rebanhos visitados, um questionário investigativo, padronizado, contendo questões sobre o manejo higiênico-sanitário do rebanho (sistema de criação, fonte hídrica, tipo de ordenha, limpeza das instalações, presença de bezerro ao pé, realização de quarentena e desinfecção de instrumentos, rotação de pastagens, suplementação alimentar, presença de esterqueiras e comedouros comuns, limpeza de úbere antes do fornecimento do colostro e contatos de bezerros com fezes de adultos), além de anotações individuais por animal quando necessário.

O exame sorológico foi realizado de acordo com o protocolo preconizado pelo kit para detecção de anticorpos frente a Mycobacterium avium subsp. paratuberculosis (MAP), Pourquier ® ELISA-IDEXX Paratuberculosis Screening. Para o cálculo dos resultados, as reações consideradas válidas foram a média do controle positivo (CPx), quando este apresentou um valor mínimo médio de OD450 de 0,350 e quando o coeficiente entre a média do CPx e o controle negativo (CN A450) foi igual ou superior a 3,00. As amostras com ponto de corte $\mathrm{A} / \mathrm{P}$, com percentagem inferior a $60 \%$ foram consideradas negativas, enquanto amostras com resultado superior a $60 \%$ e menos que $70 \%$ inconclusivas e maiores ou iguais a 70\%, positivas a presença de anticorpos frente ao MAP.

Foi utilizada a análise estatística descritiva para o cálculo das frequências relativa e absoluta dos resultados obtidos no teste sorológico. Para identificar os fatores de risco associados à infecção, foi realizada uma análise univariada das variáveis de interesse através do teste qui-quadrado de Pearson, ou Exato de Fisher, quando necessário. Posteriormente foi feita uma análise de regressão logística, considerando como variável dependente o exame sorológico (positivo ou negativo). O programa EPI INFO ${ }^{\text {TM }}$, versão 7.1.0.6., foi utilizado para a execução dos cálculos estatísticos.

Para elaboração dos mapas de distribuição geográfica das propriedades (positivas e negativas) foram coletadas coordenadas na projeção Universal Transversal Mercator (UTM) em cada propriedade visitada com o auxílio de um equipamento GPS (Global Position System). Os dados georreferenciados foram lançados nos aplicativos TerraView para o mapeamento cartográfico.

\section{RESULTADOS}

A prevalência da infecção por Mycobacterium avium subsp. paratuberculosis (MAP) foi 2,7\% (11/408; I.C. 1,4-4,9). 0 número de propriedades com pelo menos um animal positivo foi de 47,4\% (9/19), e pertenciam aos municípios de Caetés (1), Saloá (1), Garanhuns (2), Lajedo (1), Canhotinho (1), Palmeirina (1) e Bom Conselho (2). Das nove propriedades com animais sororregantes à infecção por MAP (Fig.1B), o município que apresentou maior prevalência foi Bom Conselho com animais positivos nas duas propriedades visitadas $(5,0 \%$ e $11,7 \%)$, seguido por Saloá $(10,0 \%)$, Caetés e Palmeirina (6,6\%) (Fig.2).

$\mathrm{Na}$ análise univariada dos fatores de risco observou-se associação significativa para a taxa anual de nascimentos $(\mathrm{p}=0,0390)$. Outras variáveis analisadas, porém, sem associação significativa ao nível 5\%, foram: sistema 


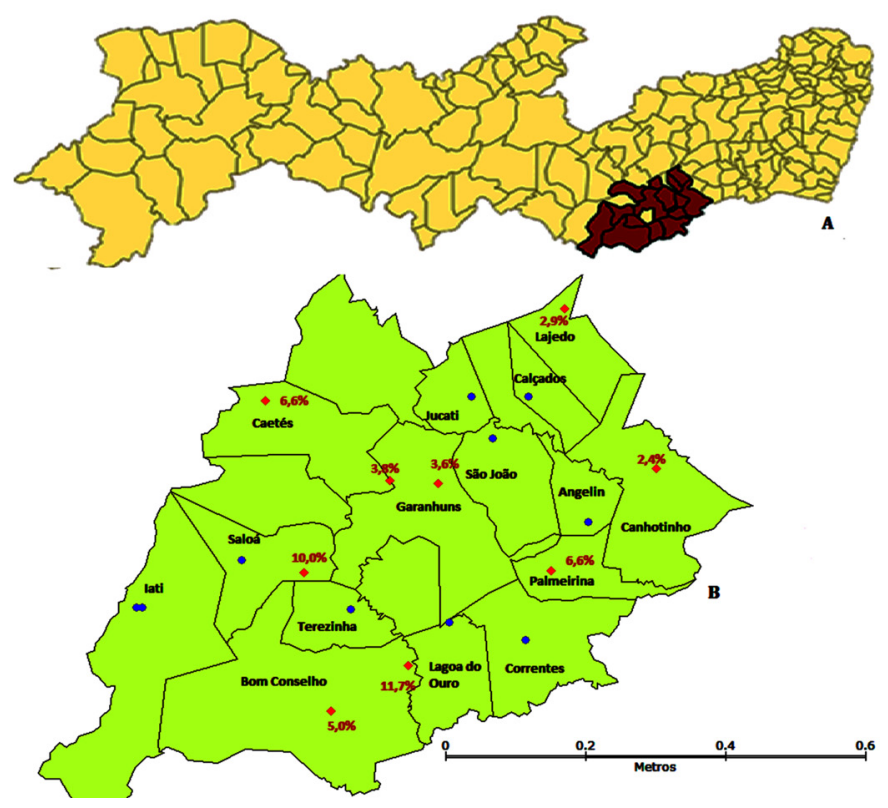

Fig.1. (A) Municípios estudados frente a infecção por Mycobacterium avium subsp. paratuberculosis (MAP) da microrregião Garanhuns em Pernambuco. (B) Prevalências e distribuição geográfica das propriedades negativas (azul) e positivas (vermelho) frente à infecção por MAP, na Microrregião Garanhuns, Pernambuco, Brasil, 2012.

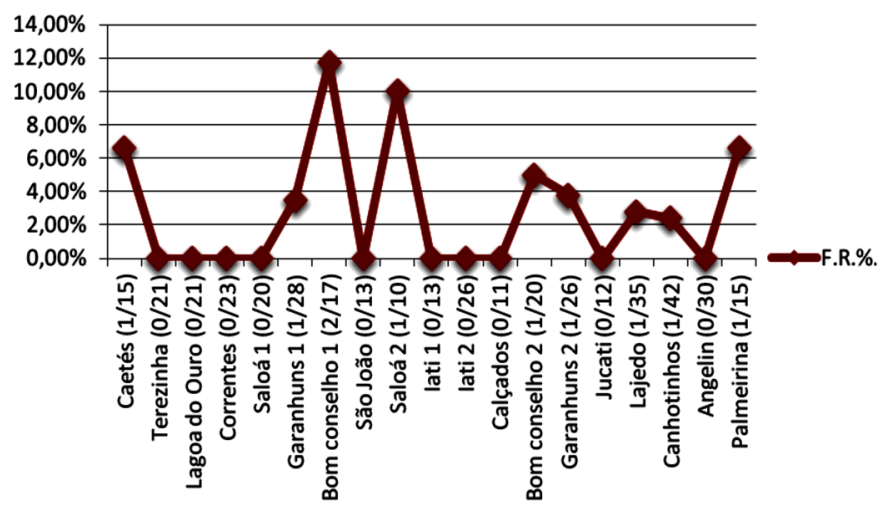

Fig.2. Frequências relativas (F.R.) de positividade pelo método ELISA, nas 19 propriedades da microrregião de Garanhuns, Pernambuco, Brasil, 2012.

de criação $(\mathrm{p}=0,8812)$, fonte hídrica $(\mathrm{p}=0,7238)$, tipo de ordenha $(p=0,3251)$, limpeza das instalações $(p=0,7082)$, presença de bezerro ao pé $(\mathrm{p}=0,7666)$, animais para reposição provenientes da propriedade $(\mathrm{p}=0,8722)$, quarentena $(p=0,6030)$, manejo reprodutivo $(p=0,6367)$, desinfecção dos instrumentos de rotina $(p=0,8888)$, rotação de pastagens $(p=0,4199)$, suplementação alimentar $(p=0,4521)$, esterqueira $(p=0,1957)$, comedouros comuns para jovens e adultos $(p=0,2480)$, contaminação dos alimentos com fezes $(p=0,1364)$, limpeza do úbere antes do fornecimento do colostro ( $p=0,8623)$, contato dos bezerros com fezes de adultos $(\mathrm{p}=0,8413)$ e piquete maternidade $(p=0,5260)$.

0 resultado da análise de regressão logística em relação ao total de propriedades analisadas, sobre os fatores de risco associados a MAP, confirmou como fator de risco com associação positiva, a taxa anual de nascimentos superior a 51 bezerros por ano (OR 3,8; IC 1,1-13,1).

\section{DISCUSSÃO}

Este é o primeiro estudo da infecção por Mycobacterium avium subsp. paratuberculosis (MAP) na microrregião estudada. A prevalência da infecção por MAP em rebanhos bovinos leiteiros da microrregião de Garanhuns (2,7\%) se mostrou inferior a alguns estudos realizados em outras regiões brasileiras, como São Paulo com 37,9\% (Fonseca et al. 1999), Pernambuco, 32,3\% (Mota et al. 2007), Rio de Janeiro com 40\% (Yamasaki et al. 2010) e Espírito Santo 11,4\% (Costa et al. 2010). Estudos recentes realizados em outros países estimaram prevalências semelhantes, como Eslovênia com 3,9\% (Küsar et al. 2011), Polônia 6,3\% (Szteyn \& Wiszniewska-Laszczych 2011) e Irã com prevalências variando de 4,2 a 7,7\% (Sadati et al. 2012).

A diferença dos resultados deste estudo em relação aos demais estados brasileiros pode ser devido ao método de diagnóstico, protocolo e fabricante dos diferentes kits ELISA, ao tipo de delineamento amostral, ou ao tipo de manejo sanitário adotado nos diferentes rebanhos. Silva (2005) ao realizar um estudo, no estado do Pará, com um kit ELISA da Suécia, com ponto de corte inferior ao deste trabalho encontrou resultado superior $(35,4 \%)$. Yamasaki et al. (2010) e Mota et al. (2007) trabalharam com propriedades com suspeita clínica ou histórico da enfermidade, o que pode ter contribuído para as elevadas prevalências registradas.

Mesmo com a baixa prevalência encontrada neste estudo, o número de propriedades com animais positivos $(47,4 \%)$ foi elevado (Fig.1B), como relatado em trabalho apresentado por Acypreste et al. (2005) que encontraram animais positivos em 100,0\% das propriedades em Goiânia, Brasil. Esse elevado número pode estar relacionado à reposição de animais sem o devido controle sanitário, pois observou - se que $100,0 \%$ das propriedades realizavam reposição de até 50 animais/ano sendo $88,8 \%$ destes provenientes do próprio rebanho. Desta forma, acredita-se que a não identificação de animais positivos pode contribuir para este quadro, uma vez que o animal, na maioria dos casos, se infecta quando bezerro e permanece dentro do rebanho eliminando o agente e contaminando o ambiente, sendo considerado como portador assintomático. A infecção dos bezerros portadores de MAP e assintomáticos pode ser um fator para a manutenção do agente no rebanho (Sweeney et al. 2006).

Observou-se, também, em $88,8 \%$ das propriedades com animais positivos que a água fornecida era parada (açudes e/ou barreiros), o que pode contribuir para o elevado número de propriedades positivas, uma vez que MAP pode permanecer viável no solo, nas fezes e na água por longos períodos, e essa água pode servir como fonte de transmissão para os animais do rebanho e rebanhos vizinhos que porventura utilizem essa água para consumo dos animais.

Em relação ao manejo de criação observaram-se animais positivos nos três tipos de criação (extensivo, intensivo e semi-intensivo), não havendo, porém, associação significativa. A presença da infecção nestes três tipos de criação indica que independente do sistema, casos de infecção por 
MAP podem acontecer. Mundialmente existem programas de controle da paratuberculose, embora ainda não existam no Brasil, estes se baseiam em procedimentos de gestão de rebanhos, tais como limpeza das instalações com desinfetantes específicos (formol 5\%, cresol, fenol e hipoclorito de sódio), e na separação dos bezerros dos bovinos adultos infectados (Lilenbaum et al. 2007).

$\mathrm{Na}$ análise de regressão logística identificou-se como fator de risco associado à infecção por MAP, a taxa anual de nascimentos superior a 51 bezerros por ano, que apresentou 3,8 vezes mais chances de infecção, quando comparados a rebanhos com taxas menores de nascimento. Este fato pode estar relacionado ao tamanho do rebanho, pois em rebanhos maiores há ausência de piquete maternidade e os bezerros menores de seis semanas tinham contato direto com fezes de animais adultos infectados e isto pode contribuir para a disseminação do agente, visto que a transmissão do MAP ocorre principalmente em pastos contaminados ou úberes sujos com fezes contaminadas.

Associado ao número de nascimentos, o tamanho e a densidade populacional podem contribuir para um maior número de casos (Dufour et al. 2004). Esse fator de risco também foi identificado por Collins \& Morgan (1991) que desenvolveram um modelo de infecção, onde discorreram sobre alguns fatores que podiam ser avaliados para o acompanhamento do curso da infecção em um rebanho, como o seu tamanho, a taxa anual de nascimentos dentro do rebanho, taxa anual de reposição dentro do rebanho, vacas infectadas, compra de novilhas infectadas e o contato efetivo entre vacas e bezerros. Teoria também confirmada por Hirst et al. (2004), que destacaram a taxa anual de nascimentos e reposição como importantes fatores de risco associados à infecção.

0 contato dos adultos e principalmente dos bezerros com pastagens contaminadas, aumentam a suscetibilidade destes perante a infecção por MAP, já que um dos fatores de risco mais importantes na transmissão do agente é o contato de bezerros com fezes de animais adultos infectados (Dore et al. 2012). A infecção pela via oral dos animais que fazem uso de pastagens adubadas naturalmente com esterco contaminado, ou que ingerem o leite de vacas que tenham úberes sujos com fezes dos currais e pastos, foram associados significativamente com o estado da infecção no rebanho, e relatados por Riemann \& Abbas (1983), Collins \& Morgan (1991), Ansari-Lari et al.(2009) e Twari et al. (2009).

Outros fatores que indicaram uma tendência associada à infecção por MAP, embora sem associação significativa, foram a não realização de quarentena ao comprar animais para reposição (OR 1,7; $p=0,6067$ ), ordenha manual (OR 1,8; $\mathrm{p}=0,3315)$, presença de bezerro ao pé (OR 1,2; $\mathrm{p}=0,7670$ ) e a falta de higienização das instalações (OR 1,4; $\mathrm{p}=0,7098$ ).

Das 19 propriedades estudadas, $14(73,7 \%)$ realizavam algum tipo de exame ao adquirir novos animais, porém, estes eram somente contra Tuberculose e Brucelose. Desta forma, com a pouca informação sanitária do rebanho, sugere-se que ao adquirir animais e introduzi-los nos rebanhos os proprietários devem realizar uma quarentena com o intuito de impedir a introdução de animais infectados por
MAP, assim como a de outros agentes infecciosos, tudo isso, deve ser associado ao correto manejo higiênico-sanitário das instalações e a rigorosa manutenção dos equipamentos de ordenha. Esses fatores já haviam sido confirmados anteriormente como fatores de risco em estudo realizado por Ferreira (2004), Goodger et al. (1996) e Tavornpanich et al. (2008), que concluíram também que a ordenha deve ser feita da forma mais higiênica e menos demorada possível e que pela implantação de melhoria nas práticas de manejo higiênico sanitário dos rebanhos, a prevalência da infecção por MAP pode ser diminuída.

A distribuição de informações e/ou orientação aos produtores sobre a enfermidade e prejuízos por ela causados, deve ser utilizada como incentivo para a promoção de uma mudança de comportamento para melhoria na implementação de medidas eficazes de controle nas propriedades (Bennett et al. 2012).

\section{CONCLUSÃO}

Concluiu-se que a infecção por Mycobacterium avium subsp. paratuberculosis (MAP) ocorre nos rebanhos bovinos leiteiros da microrregião de Garanhuns, Pernambuco, Brasil, o que indica a necessidade da implantação de medidas sanitárias de controle e campanhas de promoção em saúde para que a enfermidade não atinja maiores prevalências, diminuindo assim o número propriedades com animais positivos nesta região que representa uma das principais bacias leiteiras do estado.

Agradecimentos.- À Fundação de Amparo à Ciência e Tecnologia do Estado de Pernambuco (FACEPE) pela concessão da bolsa de mestrado do primeiro autor; e ao CNPq pelo apoio financeiro ao projeto de pesquisa (Proc. 473629/2009-7).

\section{REFERÊNCIAS}

Acypreste C.S., Juliano R.S., Riveira F.E.B., Silva L.A.F., Fioravanti M.C.S. \& Dias-Filho F.C. 2005. Uso da técnica do ELISA indireto na detecção de anticorpos anti-Mycobacterium paratuberculosis em vacas em lactação. Ciênc. Anim. Bras. 6(1):55-59.

Ansari-Lari M., Haghkhah M., Bahramv A. \& Baberan A.M.N. 2009. Risk factors for Mycobacterium avium subsp. paratuberculosis in Fars province (Southern Iran) dairy herds. Trop. Anim. Health Prod. 41:553-557.

Bennett R., McClement I. \& McFarlane I. 2012. Modelling of Johne's disease control options in beef cattle: a decision support approach. Livest. Sci. 146:149-159.

Cho J., Taver L.W., Schukken Y.H., Gomez M.I., Smith R.L., Lu Z. \& Grohn Y.T. 2012. Economic analysis of Mycobacterium avium subspecies paratuberculosis in dairy herds. J. Dairy Sci. 95(4):1855-1872.

Collins M.T. \& Morgan I.R. 1991. Economic decision analysis model of a paratuberculosis test and cull program. J. Am. Med. Assoc. 199(12):17241729.

Costa J.C.M., Pieri F.A., Souza C.F., Espeschit I.F., Felippe A.G., Santos G.M., Tobia F.L., Silva-Junior A. \& Moreira M.A.S. 2010. Levantamento sorológico de Mycobacterium avium subsp. paratuberculosis em bovinos leiteiros no estado do Espírito Santo. Arq. Bras. Med. Vet. Zootec. 62(6):1491-1494.

Dacorso-Filho P., Campos I.O.N., Faria J.F. \& Langenegger J. 1960. Doença de Johne (paratuberculose) em bovinos nacionais. Arqs Inst. Biol. Anim., Rio de J., 3:129-139.

Dias L.D., Lobato P.M.P.C., Lage A.P., Assis R.A. \& Santos T.M. 2002. Isolamento de Mycobacterium paratuberculosis a partir de fezes de bovinos suspeitos de Paratuberculose. Anais 29ํㅡㄹ Congresso Brasileiro de Medicina Veterinária, Gramado, RS. 
Doré E., Paré J., Côté G., Buczinski S., Labrecque O., Roy J.P. \& Fecteau G. 2012. Risk factors associated with transmission of Mycobacterium avium subsp. paratuberculosis to calves within dairy herd: a systematic review. J. Vet. Intern. Med. 26:32-45.

Dufour B., Pouillot R. \& Durand B. 2004. A cost/benefit study of paratuberculosis certification in French cattle herds. Vet. Res. 35:69-81.

Dupont 0.1915. Nota do Jornal do Commercio de 5 de novembro de 1915, p.8.

Driemeier D., Cruz C.E.F., Gomes M.J.P., Corbellini G., Loretti A.P. \& Colodel E.M. 1999. Aspectos clínicos e patológicos da paratuberculose em bovinos no Rio Grande do Sul. Pesq. Agropec. Bras. 19(3/4):109-115.

Ferreira L.C.B. 2004. Leite Orgânico. Caderno Técnico, Emater, Brasilia, DF.

Fonseca L.F.L., Santos M.V., Pereira C.C., Olival A.A., Heinemann M.B. \& Richtzenhain L.J. 1999. Identificação da presença de anticorpos contra $M$. paratuberculosis em rebanhos leiteiros do estado de São Paulo. Arqs Inst. Biológico, São Paulo, 66:122.

Goodger W.J., Collins M.T., Nordlund K.V., Eisele C., Pelletier J., Thomas C.B. \& Sockett D.C. 1996. Epidemiologic study of on farm management practices associated with prevalence of Mycobacterium paratuberculosis infections in dairy cattle. J. Am. Vet. Med. Assoc. 208(11):1877-1880.

Hirst H.L., Gary F.B., Morley P.S., Salman M.D., Dinsmore R., Wagner B.A., McSweeney K.D. \& Goodell G.M. 2004. Seroprevalence of Mycobacterium avium subsp. paratuberculosis infection among diry cows in Colorado and herd -level risk factors for seropositivity. J. Am. Vet. Med. Assoc. 225(1):97-101.

Janagama H.K., Lamont E.A., George S., Bannantine J.P., Xu W.W., Tu Z.J., Wells S.J., Schefers J. \& Sreevatsan S. 2010. Iron-sparing response of Mycobacterium avium subsp. paratuberculosis is strain dependent. BMC Microbiology 1:268.

IBGE 2006. Censo Agropecuário 2006. Instituto Brasileiro de Geografia e Estatística. Disponível em <http://www.ibge.gov.br/cidadesat/topwindow.htm?1> Acesso em 2 jul. 2011.

Küsar D., Oecepek M., Logar K., Pate M. \& Krt B. 2011. Seroprevalence of cattle paratuberculosis in Slovenia in 2008 and a comparison of data from current and previous studies. Slov. Vet. Res. 48(2):39-44.

Lilenbaum W., Marassi C.D. \& Oelemann W.M.R. 2007. Paratuberculosis: an update. Braz. J. Microbiol. 38:580-590.

Medeiros J.M.A., Garino Jr F., Matos R.A.T., Costa V.M.M. \& Riet-Correia F. 2012. Frequência de anticorpos para paratuberculose em bovinos no semi-árido paraibano. Pesq. Vet. Bras. 32(8):697-700.

Merkal R.S. 1975. Analysis of the effects of inaparent bovine paratuberculosis. Am. J. Vet. Res. 36(6):837-838.

Mota P.M.P.C., Pires P.S., Assis R.A., Salvarani F.M., Leite R.M.H., Dias L.D., Leite R.C., Lobato F.C.F., Guedes R.M.C. \& Lage A.P. 2009. Paratuberculosis in a dairy Gyr herd in the State of Paraíba, Brazil. Pesq. Vet. Bras. 29(9):703-706.

Mota R.A., Pinheiro-Jr J.W., Gomes M.J.P., Peixoto R.M., Maia F.C.L., Brito M.F., Chies J.A.B., Snel G.G.M., Bercht B.S. \& Juffo G.D. 2007. Paratubercu- lose em um rebanho bovino leiteiro no Estado de Pernambuco, PE. Arqs Inst. Biológico, São Paulo, 74(2):73-79.

Nakajima M., Maia F.C.L. \& Mota P.M.P.C. 1991. Diagnóstico da paratuberculose em Minas Gerais. Anais 4ํㅗ Simpósio Brasileiro em Micobactérias, Bauru, SP, Resumo 67.

Oliveira D.M., Riet-Correa F., Galiza G.J.N., Assis A.C.O., Dantas A.F.M., Bandarra P.M. \& Garin Jr F. 2010. Paratuberculose em caprinos e ovinos no Brasil. Pesq. Vet. Bras. 30(1):67-72.

Portugal M.A.S.C., Pimentel J.N., Saliba A.M., Baldassi L. \& Sandoval E.F.D. 1979. Ocorrência de paratuberculose no Estado de Santa Catarina. Biológico, São Paulo, 4(1/2):19-24.

Ramos E.T., Poester F.P., Correa B.L., Oliveira S.J., Rodrigues N.C. \& Cabarro C.E. 1986. Paratuberculose em bovinos no Estado do Rio Grande do Sul. Hora Vet. 6(34):28-32.

Riemann H.P. \& Abbas B. 1983. Diagnosis and control of bovine paratuberculosis (Johne's disease). Adv. Vet. Sci. Comp. Med. 27:481-506.

Sadati R., Jafarpour M., Mirinargesi M., Nazemi A. \& Barghi A. 2012. Prevalence of Mycobacterium avium subsp. paratuberculosis in dairy cattle bred in northern Iran by nested PCR. Global Vet. 8(3):259-263.

Santos J.A. \& Silva N.L. 1956. Sobre a primeira observação da paratuberculose no Brasil. Bolm Soc. Bras. Med. Vet. 24:5-14.

Silva E.B. 2005. Diagnóstico da paratuberculose em bovinos de corte do estado do Pará, Brasil. Dissertação de Mestrado, Núcleo de Estudos em Ciência Animal, Centro de Ciências Agrárias, Universidade Federal do Pará, Belém. 65p.

Silva N.M. \& Pizelli G.N. 1961. Estudos sobre a paratuberculose I. Diagnóstico de um caso da doença. Arqs Inst. Biol. Animal, Rio de J., 4:169173.

Sweeney R.W., Uzonna J., Whitlock R.H., Habecker P.L., Chilton P. \& Scott P. 2006. Tissues predilection sites and effect of dose on Mycobacterium avium subs. paratuberculosis organism recovery in a short-term bovine experimental oral infection model. Vet. Sci. 80:253-259. Disponível em <http://www.nal.usda.gov/awic/pubs/johnes/2006.htm>

Szteyn J. \& Wiszniewska-Laszczych A. 2011. Seroprevalence of bovine paratuberculosis infections in Poland Med. Wet. 67(9):622-625.

Tavornpanich S., Johnson W.O., Anderson R.J. \& Gardner I.A. 2008. Herds characteristics and management practices associated with seroprevalence of Mycobacterium avium subsp. paratuberculosis infection in dairy herds. Am. J. Vet. Res. 69(7):904-911.

Thrusfield M.V. 2004. Epidemiologia Veterinária. 2ª ed. Roca, São Paulo.

Twari A., Vanlleuwen J.A., Dohoo I.R., Keefe G.P., Haddad J.P., Scott H.M. \& Whiting T. 2009. Risk of factors associated with Mycobacterium avium subspecies paratuberculosis seropositivity in Canadian dairy cows and herds. Prev. Vet. Med. 88(1):32-41.

Yamasaki E.M., Tokarnia C.H., Galvão A., Gomes M.J.P., Chies J.A.B., Veit T.D., Aragão A.P. \& Brito M.F. 2010. Aspectos clínicos-patológicos e controle da paratuberculose em rebanho bovino leiteiro. Pesq. Vet. Bras. 30(11):921-932. 